\title{
Cost, resources, and energy efficiency of additive manufacturing
}

\author{
Piotr Dudek ${ }^{1, *}$ and Krzysztof Zagórski ${ }^{1}$ \\ ${ }^{1}$ AGH University of Science and Technology, Faculty of Mechanical Engineering and Robotics, al. \\ A. Mickiewicza 30, 30-059 Kraków, Poland
}

\begin{abstract}
Additive manufacturing (AM) is the process of joining materials to make objects from Computer Aided Design (CAD) model data, usually layer upon layer, as opposed to using subtractive manufacturing methods. The use of rapid prototyping technologies has increased significantly in recent years. These new techniques, while still evolving, are projected to exert a profound impact on manufacturing. They can reduce energy use and time to market and offer industry new design flexibility. We include a brief study on the cost and energy efficiency of selected methods of additive manufacturing compared to traditional methods of manufacturing parts. One common claim is that 3D printers are more energy-efficient than other manufacturing technologies. We present energy efficiency and time requirements for producing a typical mechanical part and a very complicated element, using both traditional manufacturing and rapid prototyping methods. This paper represents an attempt to answer the questions of when 3D printing can be used efficiently and of choosing the appropriate technology on the basis of batch size, element size, complexity, and material requirements.
\end{abstract}

\section{Introduction}

Rapid prototyping represents a relatively novel technology in manufacturing, associated with potentially strong stimuli for sustainable development. As part of digital fabrication technology, Additive Manufacturing (AM) systems are able to manufacture threedimensional components and products directly from raw material and 3D design data. Synonyms used to refer to this technology include additive techniques, layered manufacturing, rapid prototyping, digital manufacturing, and solid freeform fabrication [1]. The layer-by-layer operating process of these systems does not require the use of tools, moulds or dies. The main feature of AM methods is their flexibility in terms of the design of a product, making these methods responsive to almost any shape. Adoption of these technologies announces a future in which value chains are shorter, more localised, and more collaborative, while offering significant sustainability benefits. Observers of technology speculate that Additive Manufacturing will have a profound economic impact on the manufacturing sector and, indeed, on the society as a whole $[2,3]$.

\footnotetext{
*Corresponding author: pdudek@agh.edu.pl
} 
Compared to conventional manufacturing, such as machining, forging, injection moulding, casting, and other processes, AM has certain advantages. Firstly, AM can reduce environmental impact due to its avoidance of the tools, dies, moulds, and material waste associated with conventional manufacturing. Secondly, and most importantly for designers, this technology enables the manufacture of parts with novel geometric designs that would be difficult or impossible to achieve using conventional manufacturing processes. Thirdly, novel geometries enabled by AM technologies can also lead to environmental benefits or improved performance in a final product containing elements produced by AM. For example, AM is used by aircraft companies to produce parts that weigh less, which can lead in turn to greater aircraft fuel efficiency. General Electric uses 3D printing technology to produce fuel nozzles for the next-generation LEAP jet engine which are five times more durable than the previous model. 3D printing enabled engineers to design them as a single part rather than 20 individual parts, reducing the number of brazes and welds that would have been necessary using traditional methods $[4,5]$.

The first environmental studies on AM processes proposed the potential for gains in terms of environmental impact compared with more traditional processes, such as machining [6-8].

Table 1. Classification of AM technology [9]

\begin{tabular}{|c|c|c|}
\hline Technology & Description & Related technologies \\
\hline $\begin{array}{l}\text { Vat } \\
\text { photopolymerisation }\end{array}$ & $\begin{array}{l}\text { Liquid photopolymer in a vat is } \\
\text { selectively cured by light-activated } \\
\text { polymerisation. }\end{array}$ & $\begin{array}{l}\text { Stereolithography } \\
\text { (SLA), Digital Light } \\
\text { Processing (DLP) } \\
\end{array}$ \\
\hline Binder jetting & $\begin{array}{l}\text { The binder jetting process uses two } \\
\text { materials: a powder-based material } \\
\text { and a binder. A liquid bonding agent } \\
\text { is selectively deposited to join } \\
\text { powder materials. }\end{array}$ & 3DP (3D Printing) \\
\hline Material jetting & $\begin{array}{l}\text { Material jetting creates objects in a } \\
\text { method similar to a two-dimensional } \\
\text { inkjet printer. Droplets of build } \\
\text { material are selectively deposited. }\end{array}$ & $\begin{array}{l}\text { Multi-jet modelling } \\
\text { (MJM), PolyJet, Droplet } \\
\text { on Demand (DoD) }\end{array}$ \\
\hline Material extrusion & $\begin{array}{l}\text { Material is drawn through a nozzle, } \\
\text { where it is heated and then deposited } \\
\text { layer by layer. The nozzle can move } \\
\text { horizontally, and a platform moves } \\
\text { up and down vertically after each } \\
\text { new layer is deposited. }\end{array}$ & $\begin{array}{l}\text { Fused deposition } \\
\text { modelling } \\
(\text { FDM) }\end{array}$ \\
\hline Sheet lamination & $\begin{array}{l}\text { Sheets of material are bonded to form } \\
\text { an object. }\end{array}$ & $\begin{array}{l}\text { Laminated object } \\
\text { manufacturing (LOM), } \\
\text { ultrasonic consolidation } \\
\text { (UC) }\end{array}$ \\
\hline Powder bed fusion & $\begin{array}{l}\text { Thermal energy selectively fuses } \\
\text { regions of a powder bed. }\end{array}$ & $\begin{array}{l}\text { Electron beam melting } \\
\text { (EBM), selective laser } \\
\text { sintering (SLS), } \\
\text { selective metal melting } \\
\text { (SLM), direct metal } \\
\text { laser sintering (DMLS) }\end{array}$ \\
\hline $\begin{array}{l}\text { Directed energy } \\
\text { deposition }\end{array}$ & $\begin{array}{l}\text { Focussed thermal energy is used to } \\
\text { fuse materials by melting as the } \\
\text { material is being deposited. }\end{array}$ & $\begin{array}{l}\text { Laser Engineering Net } \\
\text { Shaping (LENS) }\end{array}$ \\
\hline
\end{tabular}




\section{Additive Manufacturing technologies}

Although the term '3D Printing' is used by the media as a synonym for all additive manufacturing processes, there are actually many different processes which vary in their method of layer manufacturing. These processes differ depending on the material and technology used, and can be classified in a few categories (Table 1).

The AM processes can also be classified based on the state of the starting material used [1].

\section{Environmental implications}

Since the introduction of AM in the 1980s, the benefits of producing small quantities of complex parts rapidly have been well understood among manufacturing circles. Despite this, the industry is just beginning to understand exactly how transformative the technology will be within the future of manufacturing [10 - 12].

Today, the most established use of additive manufacturing is making prototypes. 3D printers can quickly produce complex pieces in small quantities for the purpose of evaluating a design. Mould makers and plastics processors frequently use additive equipment in precisely this way - to test a part before the tooling is finalised and before full-scale production begins. Additive manufacturing and traditional manufacturing face different trade-offs, with each process likely to play a role in the deployment of manufacturing capabilities. AM has the potential to vastly accelerate innovation, compress supply chains, minimise materials and energy usage, and reduce waste $[5,13,14]$.

The following are the some of the most significant benefits of additive manufacturing, highlighting where the technology is taking us today:

- Less waste: building objects up layer by layer, instead of using traditional machining processes that cut away material, can reduce material needs and costs by up to $90 \%$. AM can also reduce the 'cradle-to-grave' environmental footprints of component manufacturing through avoidance of the tools, dies, and material scraps associated with conventional machining processes.

- Lower energy consumption: AM saves energy by eliminating production steps, using substantially less material, enabling reuse of by-products, and producing lighter products.

- Innovation and design freedom: in traditional machining, every complex detail has to be produced through additional tool paths or other extra steps. By comparison, the complexity of a part in additive manufacturing adds very few extra considerations, or none. A part can be made purely for functionality, without manufacturing-related constraints. Design engineers have only started to explore the implications of this.

- Short lead times: Items can be fabricated as soon as the 3D digital description of the part has been created, eliminating the need for expensive and time-consuming part tooling and prototype fabrication. As soon as the part is printed, engineers can begin testing its properties, instead of waiting weeks or months for a prototype or part to come in.

- Light weight: With the elimination of tooling and the ability to create complex shapes, AM enables the design of parts that can often be made to the same functional specifications as conventional parts, but with less material.

Compared to other methods, additive manufacturing can produce parts quickly, because it is not necessary to perform all tasks with all the necessary technology for preparing for manufacture, and it is possible to produce parts with complicated shapes. The costs of parts are readily predictable. However, it must be mentioned that in these technologies, though 
they produce less waste, raw material is more expensive than material used in conventional types of manufacturing.

\section{Energy usage in the SLS process}

The Department of Manufacturing Systems, Faculty of Mechanical Engineering and Robotics, AGH, conducted a study to determine power usage in the production of parts using selective laser sintering (SLS) technology. To do this, a platform was prepared, including 75 parts for a total height of $92 \mathrm{~mm}$ for an EOS Formiga P100 (Fig. 1). Parts were printed using polyamide PA2200. The measured build time was 12.5 hours plus an additional 3 hours of preheating, with the temperature set at $172^{\circ} \mathrm{C}$. Cooling time was 12.5 hours.

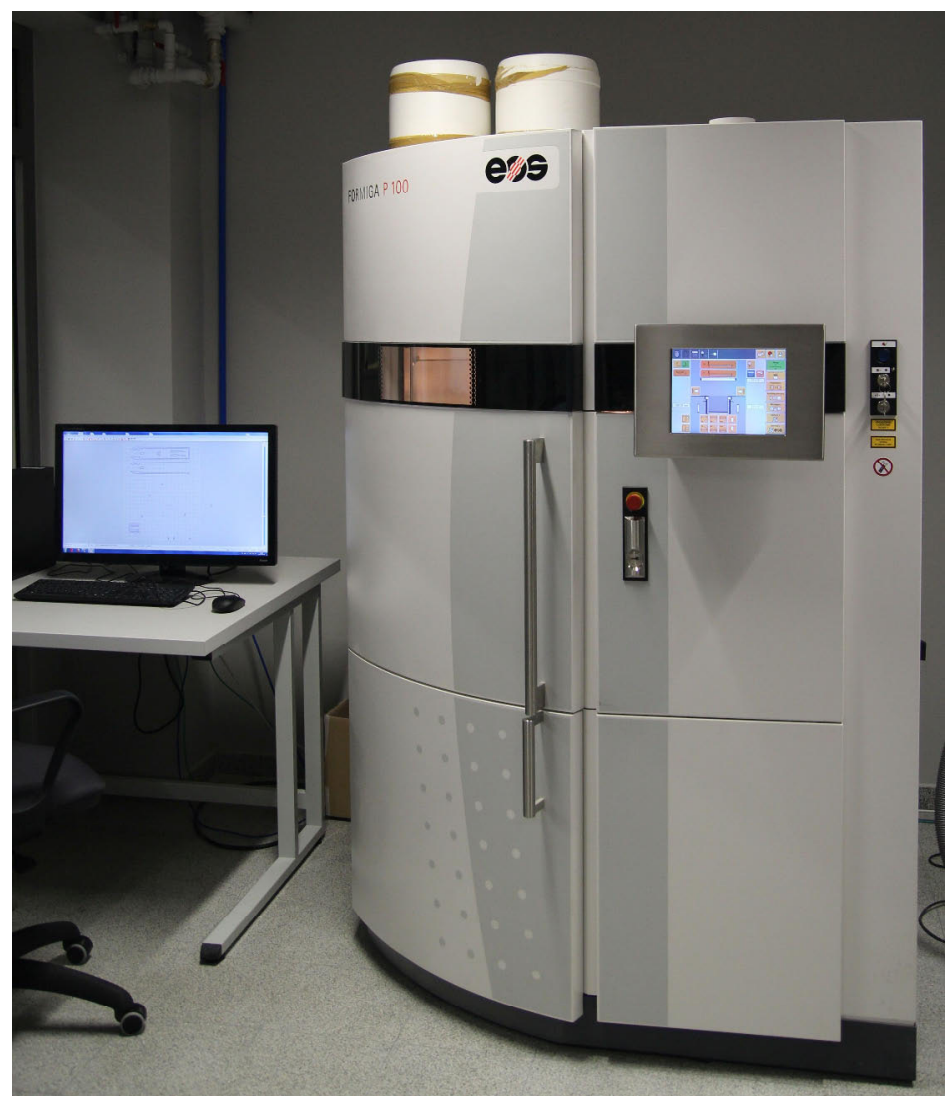

Fig 1. SLS machine: EOS Formiga P100 


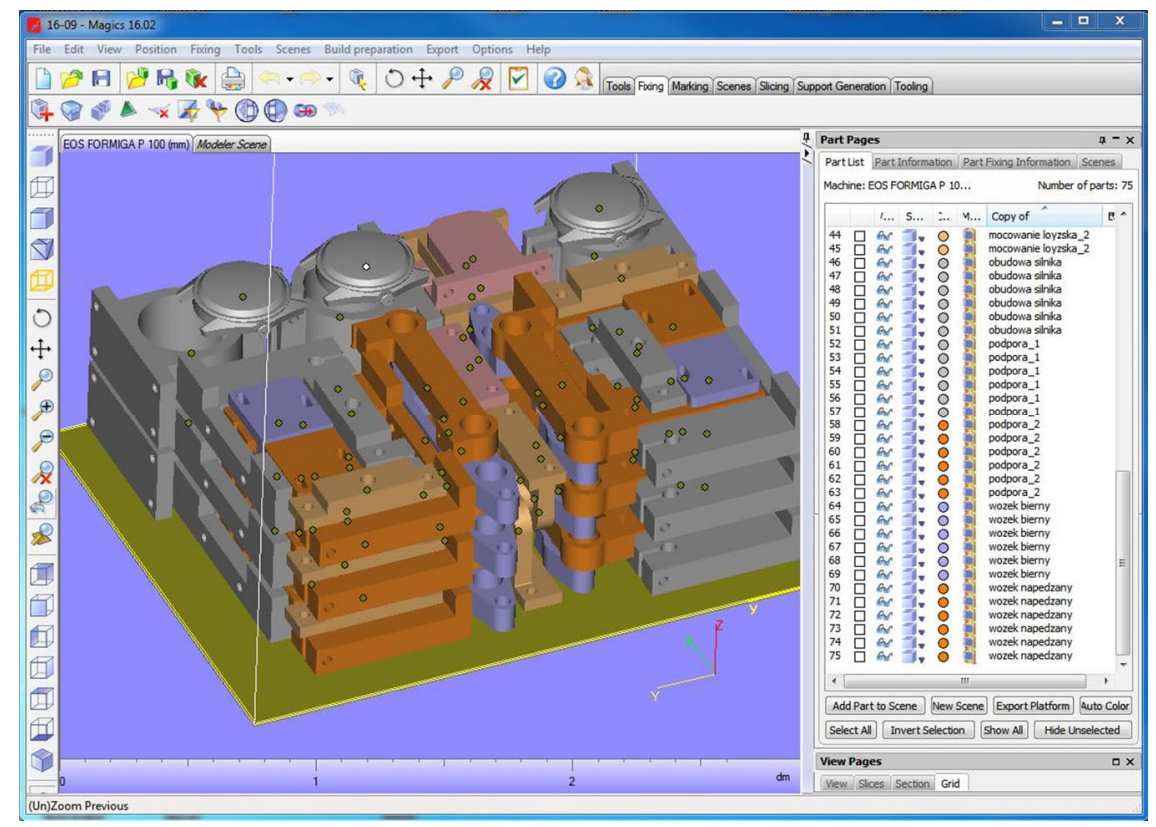

Fig. 2. Prepared platform for the test job: 75 parts, $92 \mathrm{~mm}$ total height, 11:38:00 printing time

Before printing was started on the test job, the work and removal chambers, heaters and air channels were cleaned and the optics and pyrometer were checked. Parts were positioned using Magics software (Fig. 2), and, after the arrangement was completed, the parts were merged and exported as one STL file. The volume of this part was 1,196,500 $\mathrm{mm}^{3}$; it was located in a bin with the dimensions $200 \times 250 \times 92 \mathrm{~mm}$. After some calculation it can be determined that the useful portion of this volume is approximately $26 \%$.

After printing and waiting 12.5 hours for cooling of the printed parts, the machine was cleaned and the building bin removed for post-processing of the parts. The parts were removed from the bin and cleaned with a sandblasting machine. The rest of the powder was sieved and stored for reuse in future jobs. It should be noted that this material should be mixed (new powder with used; the best ratio is 50/50) for stabilising the printing process and to minimise waste. Some types of material cannot be reused, for example polyamide PA12 filled with aluminium (Alumide); others, for example PrimeCast or powder with a polystyrene base, can be reused $100 \%$ after sieving. Because of this, the cost of the material for printing depends not only on the volume of printing and cost of material, but also on the ability to reuse powder. The best ratio is associated, of course, with material based on polystyrene, but this material has poor mechanical and thermal properties, and is used only to create patterns for investment casting, master patterns for vacuum casting, or production of lost patterns for the plaster and ceramic shell casting processes. After certain printing processes, leftover material cannot be reused, and thus becomes waste. In analysing actual printing jobs, it can be observed that over a long time period, waste for SLS averages $20-40 \%$ for each job. The amount of material waste is affected by a number of factors, including the size of the printed piece, the preparation of the machines, packing density when preparing to print, etc. On every job, some material is removed by a vacuum cleaner when cleaning and preparing the machine for the next job; this quantity is the same for large and small jobs. For less waste, a good solution is to pack dense parts, and, if possible, to reduce the height of the printed piece. This is an arduous process, even with the use of automatic placement tools, but it can significantly reduce waste. Since the SLS process for plastic parts needs no support structure parts, parts can be placed one over 
another. This process is characterised by relatively little waste compared to other AM technologies.

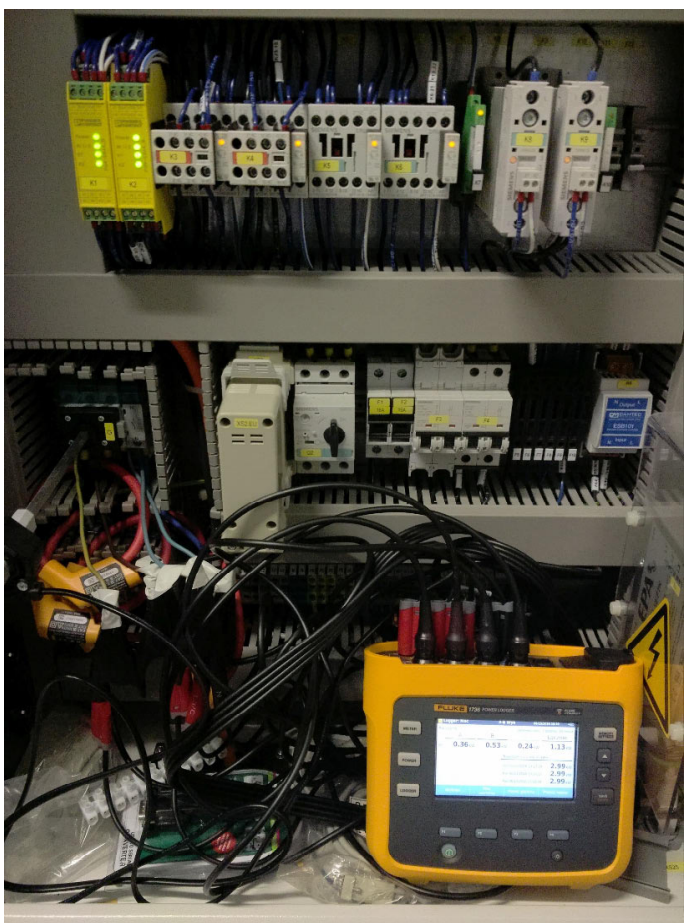

Fig. 3. Fluke logger connected to the Formiga P100

In observing the print process, it would seem that the process is energy-intensive. The machine must heat the working and removal chambers and provide power to the motors, laser, and electronic circuits, and the printing process itself is time-consuming. To examine the power usage of the Formiga P100, the Fluke 1736 energy logger was used (Fig. 3). Because the laser circuit, electronics, and heaters use different phases, it is possible to measure energy usage for these different elements.

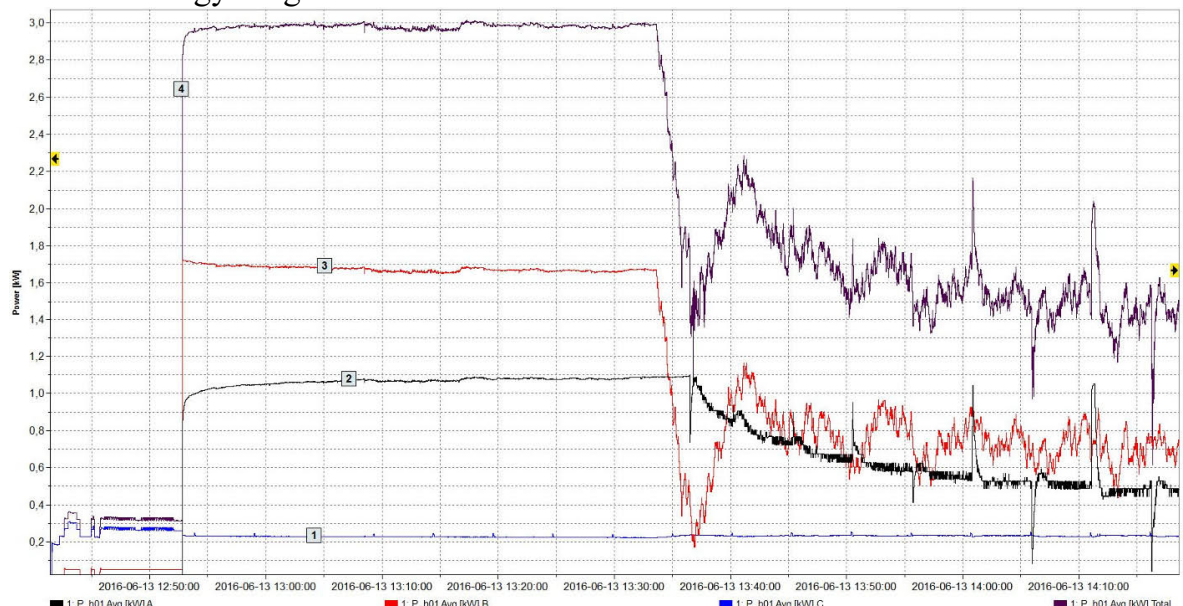

Fig. 4. Starting the machine to preheating phase - total time, $180 \mathrm{~min}$. 1-laser circuit; 2 - electronics, motors, and removal chamber; 3 - heater circuit; 4 - total power 
Fig. 4 shows the energy usage of the Formiga P100 from starting the machine to the preheating stage. The machine was switched on after it had cooled to room temperature. After the machine starts and become operable the process of distributing the powder on the working bed begins. Next, the process of preheating is initiated, seen as a rise in the power during phases 2 (removal chamber) and 3 (working chamber). Total power for preheating does not exceed $3 \mathrm{~kW}$. After 40 minutes of heating, the power needed for this operation decreases, and for $140 \mathrm{~min}$ the power is regulated as the temperature in the chambers slowly increases.

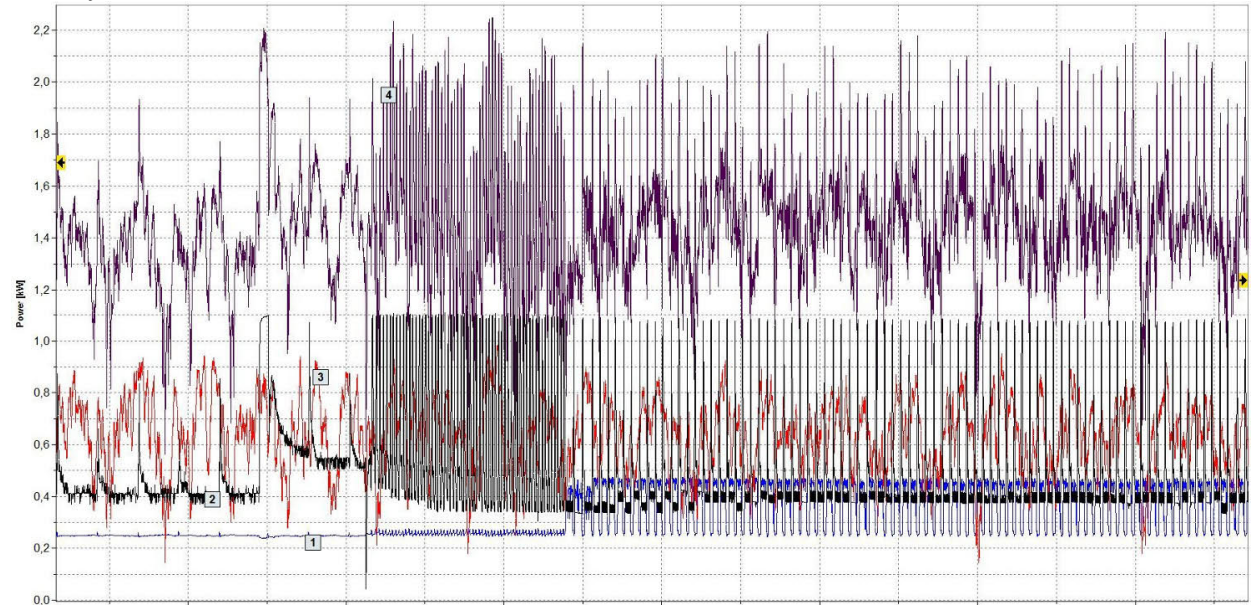

Fig. 5. Preheating phase - start of job. 1- laser circuit; 2 - electronics, motors, and removal chamber; 3 - heater circuit; 4 - total power

After the preheating phase, the process and removal chambers are heated up to working temperature (approximately 12 minutes); then, printing is started. The first 60 layers are empty, so the laser is idle; after that, the laser starts working (the peaks in line 1, Fig. 5), and the chambers are also heated to the desired working temperature; due to the new applied layer of powder, the temperature must be raised. Printing time is 12.5 hours, and the process uses an average of $1.4 \mathrm{~kW}$ of power.

The last 40 layers are also empty, and after this the cooling phase begins. The laser, heaters, and motors are switched off, and only the electronics and the nitrogen generator (which needs no power) work; here, an average of $0.5 \mathrm{~kW}$ was used. It can be seen that heating is the most energy-intensive part of the SLS process, and uses $50 \%$ of the required power. The total energy used for the production of 75 parts was approximately $29 \mathrm{kWh}$, or 104.4 MJ. It must be mentioned that this represents the energy of the printing machine; the power used for the compressor or machines for post-processing was not measured.

\section{Conclusions}

The RP industry continues to expand. Current research on additive manufacturing costs reveals that this technology is cost-effective for manufacturing small batches. Due to the complexities of measuring additive manufacturing costs, the current study is limited to the scope of energy effectiveness and efficiency.

Currently, research also reveals that material costs constitute a major proportion of the cost of a product produced using additive manufacturing, but a number of factors, including build orientation, envelope utilisation, build time, energy consumption, product design, and labour, complicate attempts to minimise the cost of additive manufacturing. Even a simple 
change in part orientation and the part's position in the building chamber can significantly reduce energy and material consumption. These issues must be considered when analysing the cost of additive manufacturing, making it difficult and complicated to minimise costs.

The results and analysis support some major recommendations for future work to reduce SLS energy consumption:

- Build volumes should be packed as densely as possible to maximise the ratio of part output per build height;

- Time and energy consumption for the preheating phase, preparation, and laser scanning of each layer should be reduced;

- Material-related energy consumption should be improved by engineering longterm recyclable powder and by reducing powder loss during handling.

The scope of future energy studies could also be extended to include factors such as distribution, waste handling, and infrastructure. AM technology introduces greater freedom and expanded possibilities to the design stage, which may further improve the sustainability of a designed product and reduce its environmental impact during the service stage, factors that were not considered in this study.

\section{References}

1. I. Gibson, D. Rosen, B. Stucker, Additive Manufacturing Technologies (Springer, 2015)

2. R. A. D’Aveni, 2013. Harv. Bus. Rev. 91, 34-35 (2013)

3. S.S. Muthu, M. M. Savalani, Handbook of Sustainability in Additive Manufacturing (Springer 2016)

4. Quadrennial Technology Review 2015, Innovating Clean Energy Technologies in Advanced Manufacturing. U.S. Department of Energy

5. Quadrennial Technology Review 2015, Additive Manufacturing Technology Assessment, U.S. Department of Energy

6. R. Huang, M. Riddle, D. Graziano, J. Warren, S. Das, S. Nimbalkar, J. Cresko, E. Masenet, J. Clean. Prod. 135, 1559-1570 (2016)

7. M. Gebler, A. J.M. Schoot Uiterkamp, C. Visser, Energ. Policy 74, 158-167 (2014)

8. Wohlers Report 2014, 3D Printing and Additive Manufacturing State of the Industry, Annual Worldwide Progress Report, Wohlers Associates, 2014

9. The ASTM International Committee F42 on Additive Manufacturing Technologies

10. 3-D Printing: Sustainability Opportunities and Challenges, BSR Report 2015

11. C. McAlister, J Wood, eceee Industrial Summer Study (2014),

12. T. S. Dougles, S.W. Gilbert, Costs and Cost Effectiveness of Additive Manufacturing, NIST Special Publication 1176 (2014)

13. M. Despeisse, S. Ford, Centre for Technology Management working paper series, University of Cambridge, 3, 2015

14. S. Huang, P. Liu, A. Mokasdar, L. Hou, Int. J. Adv. Manuf. Tech. 67, 1191-1203 (2013) 